\title{
DESIGN DE SOM COMO DESIGN DE ESCUTA
}

André Luiz Gonçalves de Oliveira

Universidade do Oeste Paulista - UNOESTE, Design Gráfico e FACLEPP, Curso de Música, Presidente Prudente, SP Email: alguns@gmail.com

\section{RESUMO}

O texto que segue é uma descrição de algumas reflexões no contexto da pesquisa realizado durante os anos de 2017 e 2018 na Universidade do Oeste Paulista, sob o título de "Design de som como design de escuta". A partir das ideias de T. Ingold contra o conceito de paisagem sonora, proponho um caminho para o entendimento do som enquanto experiência de corpos com características próprias escutando (agindo) com outros corpos, em lugares específicos. Uma das reflexões centrais do presente artigo é a de que planejar os sons de algum lugar não é exatamente manipular softwares e calcular coordenadas matemáticas, é antes projetar a escuta de diferentes grupos de pessoas em determinados locais. Com isso o design de som precisa ser entendido como design de escuta de pessoas específicas em seus lugares de escuta e vida.

Palavras-chave: Estudos de escuta; design de som; design de escuta; paisagem sonora, sonologia.

\section{SOUND DESIGN AS LISTENING DESIGN}

\begin{abstract}
The following text is a description of some reflections in the context of the research project, carried out during the years 2017 and 2018 at Universidade do Oeste Paulista, under the title of "Sound Design as Listening Design". From the ideas of T. Ingold against the concept of soundscape, I propose a way for the understanding of sound as an experience of specific bodies listening (acting) with other bodies, in specific places. One of the central reflections of this article is that planning the sounds of a place is not exactly manipulating software and calculating mathematical coordinates, rather it is designing listening to communities of people in certain places, in everyday situations, or in images and artistic representations.
\end{abstract}

Keywords: Listening studies; sound design; listening design; soundscape; sonology 


\section{INTRODUÇÃO}

A sub-área de estudos que se denomina por design de som envolve basicamente o planejamento e arranjo dos eventos sonoros que alguém, ou um determinado grupo, vai escutar em uma determinada situação, por um período específico de tempo. Em suas diversas possibilidades de aplicação, como no cinema por exemplo, os criadores operam por meio de softwares ou equipamentos que lhes permite planejar e modelar os eventos sonoros, os eventos mecânico-vibratórios, que estarão disponíveis nos locais os quais as pessoas poderão escutá-los. Na sonoplastia de teatro também há operações que realizam os eventos sonoros planejados para cada situação. E na música, sobretudo no contexto da música eletroacústica, o compositor trabalha planejando e construindo eventos sonoros para oferecê-los em uma certa disposição a seus ouvintes.

Nas artes que se fazem por meio da escuta se opera na construção de imagens sonoras que serão experimentadas esteticamente. É importante se observar que o conceito de imagem aqui empregado está ligado à concepção espinosiana da noção, como conjunto das percepções de algum evento. Nesse sentido há imagens para as diversas modalidades perceptivas e suas interrelações. O trabalho, portanto, do design de som é a elaboração dessas imagens sonoras para serem experimentadas, percebidas, por vezes esteticamente, por vezes enquanto comunicação.

Entretanto, os estudos que a refeida pesquisa procedeu, com leituras de M. MerleauPonty, de Tim Ingold e de E. Dussel, indicam que é relevante readequar as descrições sobre o que vem a ser design de som. A partir dos argumentos da fenomenologia e dos estudos decoloniais, tem sido imperativo descrever o planejamento de som enquanto planejamento de escuta de lugares específicos, por grupos de pessoas com características próprias. E esse novo encaminhamento da descrição do que vem a ser design de som contraria o entendimento de senso comum e da lógica da modernidade e colonialidade, que compreende tal ação como especificamente o planejamento dos processamentos feitos em um sinal elétrico, ou seus referentes códigos binários digitais.

Ao se desenvolver a ideia de som como imagem do lugar de escuta é preciso pensar que o que se planeja não é outra coisa se não a percepção das pessoas, a maneira como pessoas experimentam no mundo a sua volta. E o que a maioria dos manuais técnicos de "Design de som" oferece é basicamente um conjunto de habilidades de operação sobre um sinal elétrico que será padrão vibratório em um meio específico. Nesse planejamento não se trata das pessoas que vão escutar. Não se trata das emoções possíveis ou prováveis que essas pessoas sentirão a partir dessa escuta. Ou ainda, não se trata nessa operação de planejamento de som de outra coisa se não números e fórmulas que operam com esses números. Para esse paradigma cartesiano dualista, as representações abstratas e metafísicas controlam o mundo da matéria e da fisicalidade.

Portanto o objetivo do presente estudo é propor uma descrição de design de som enquanto design de escuta. Entendendo que a diferença central entre as duas denominações está em que a segunda expressão traz à luz as comunidades pessoas específicas e seus lugares de experiências, que encontram-se escondidos atrás dos números, fórmulas e modelos representacionais que o paradigma cartesiano oferece junto da noção de som, como algo que independe da escuta. Dizendo de outra forma, o texto a seguir espera contribuir para mostrar que planejar som não é exatamente movimentar botões, fazer cálculos e ligar cabos em caixas de som. É antes planejar possibilidades de experiências das pessoas em um lugar e tempo próprios. É oferecer condições de partilha de emoções e sentimentos que produzem sentidos e afetos diversos nos contextos específicos da vida das comunidades de pessoas envolvidas.

\section{METODOLOGIA}

Essa pesquisa teve como objetivo refletir sobre conceitos e descrições das práticas artísticas que utilizam a escuta. Dessa maneira a metodologia envolveu diferentes etapas de 
leituras comparativas entre os autores referidos na lista de bibliografia. É importante atentar que essa pesquisa parte de outras anteriores, que retoma seus temas e encaminhamentos. 0 projeto que aqui se conclui é o terceiro a partir da pesquisa desenvolvida nos anos de 2014 e 2015, chamada de "Caracterização da Paisagem Sonora de Presidente Prudente - SP". Que por sua vez mostrou a necessidade de se pensar em formas de categorizar a paisagem sonora e proporcionou o projeto de pesquisa que ocorreu entre 2015 e 2017 intitulado: "Desenvolvimento de metodologia para classificação de paisagens sonoras". Como fruto dessa atividade é que se preparou e realizou esse terceiro projeto de pesquisa, cujos resultados ora se apresentam.

\section{RESULTADOS}

Enquanto pesquisa teórica o principal resultado são as reflexões que se encaminham da hipótese central dessa pesquisa que se confirma e se configura muito articulada, de que planejar ou projetar som precisa ser descrito como projetar e planejar as ofertas de experiências para pessoas específicas em lugares específicos. E que os recursos generalizantes, universais, que existem para projetar "som" não levam em conta as pessoas e suas possibilidades de partilha de emoções. Essa conclusão é central para que se pense a partir daqui possibilidades de se reconfigurar os planejamentos dos diversos lugares nos quais diversas pessoas vivem e escutam.

O próprio conceito de "lugar de escuta" aparece no contexto dessa pesquisa enquanto noção chave para que se compreenda o que a noção de som esconde, a saber, a vida dos corpos que escutam, e dos lugares nos quais escutam, das experiências possíveis às escutas em tais lugares. O presente projeto permitiu que se aproximem aspectos teóricos da fenomenologia, especialmente em sua vertente externalista e enaccionista, com conceitos dos estudos em decolonialidade. Provavelmente um dos principais resultados dessa pesquisa seja colocar par a par essas teorias e apontar novas descrições do design de som e das artes sonoras para além do paradigma cartesiano moderno e colonial.

Em suma, abre-se a perspectiva de pesquisar os diferentes lugares de escuta e suas possibilidades estéticas e éticas de acordo com a participação de diferentes corpos, com suas diferentes vontades, possibilidades e especificidades históricas. Pode-se seguir o caminho realizado por esses três projetos de pesquisa encaminhados desde 2014, citados anteriormente, por um trajeto que se ocupe em descrever tais experiências de grupos de pessoas em suas dinâmicas, nos lugares de escuta em que vivem, considerando relacionar estética, poética e ética à luz de estudos de fenomenologia e decolonialidade.

\section{DISCUSSÃO}

As artes que fazem uso da escuta, na tradição musical ocidental, foram construídas e descritas distante da experiência de escutar feita por determinados corpos agindo em lugares específicos. A noção de som tem sido utilizada, ao menos desde as origens da psicofísica moderna em meados do século XIX, como causa da escuta. E nessa inversão da lógica tem ainda se reificado e prescindido da escuta, dos corpos que escutam e dos lugares nos quais esses corpos escutam. Esses fatos localizados e criticados pela fenomenologia, ainda mais quando aprofundados pela novíssima vertente chamada de $4 E$ Cognition, relacionam-se diretamente com conceitos fundamentais de teorias dos estudos decoloniais. Se o conhecimento é descrito como corporificado, situado, estendido e enactivo, conforme anuncia a corrente chamada de $4 E$ Cognition, é impossível não abordar aspectos dos corpos que escutam, de suas situações, de suas extensões, das interações que a escuta oferece para tais corpos em tais meios.

Ao se aproximar dessas perspectivas teóricas a forma de descrever aquilo que se tratava até aqui por paisagem sonora, conforme o conceito postulado por R. M. Schafer e seus colegas na década de 1970, precisa ser reconfigurada. O antropólogo Tim Ingold tece uma relevante e fundamental crítica ao conceito schaferiano de paisagem sonora. Ele alcança tal conceito a partir 
de uma crítica a noção de paisagem como a constituição de uma mundo desvinculado do ser que o faz, enquanto se faz nesse mundo.

Ao invés de pensar em nós mesmos apenas como observadores trilhando nosso caminho ao redor dos objetos espalhados pelo chão de um mundo ja formado, devemos imaginarnos, em primeiro lugar, como participantes, cada um imerso com todo nosso ser nas correntes de um mundo em formação: na luz solar nós vemos, a chuva na qual ouvimos e o vento no qual sentimos. Participação não se opõe a observação, mas é uma condição para isso, assim como a luz é uma condição para se ver as coisas, o som para ouvi-las e a sensação para senti-las. (INGOLD, 2015, p. 197)

Para Ingold (2015) o som não é algo que está lá adiante, formando uma paisagem com objetos que eu escuto, mas antes, é a ação de escutadores interagindo em lugares de escuta específicos. A condição em que se escuta é aquela em que se vive e por isso o antropólogo afirma que não se escuta o som, como algo que está lá, mas se escuta no som, no mundo no qual a vida se faz ao mesmo tempo em que faz o mundo.

A crítica contra a noção de Paisagem Sonora, de T. Ingold (2015) inicialmente remete-se ao fato de que o que se percebe como paisagem é muito mais um todo perceptivo do que uma fatia do mundo. Poderia se falar em uma imagem perceptiva, nos termos de Espinosa. A vida do dia-adia não acontece dividida em dimensões visuais, auditivas, olfativas, etc. Mas, ao contrário, quando se busca escutar o lugar onde se está, odores, sabores e imagens visuais encontram-se sempre integradas àquilo que se ouve. Então, separar só o que é audível é novamente caminhar para um mundo purificado, preparado, apartado do resto da vida para análise, em suma, um nãomundo.

Um outro ponto central trazido pelo antropólogo Tim Ingold (2015) é a objeção à própria noção fetichizada de som, enquanto existente independentemente da percepção de alguém. Ele trata o som (mesmo gravado/armazenado em um suporte físico) como capacidade de ouvir, antes de tratá-lo como uma representação de um fenômeno mecânico-vibratório. Segundo o autor (INGOLD, 2015, p. 208) (...) o som é outra maneira de dizer "eu posso ouvir". (...). Pois o som, (...), não é o objeto mas o meio de nossa percepção. É aquilo em que ouvimos. De alguma forma Ingold propõe reverter a inversão da lógica reificante que trata a representação como primeira, com relação a experiência. É basicamente o aprofundamento da abordagem fenomenológica proposta por Maurice Merleau-Ponty.

O verdadeiro Cogito (...) não substitui o mundo pelo significado do mundo. Ele reconhece, ao contrário, meu próprio pensamento como um fato inalienável, e elimina qualquer espécie de idealismo, revelando-me como "ser no mundo". (MERLEAU-PONTY, 1996, p. 8).

Para a fenomenologia se o ser só existe enquanto "ser no mundo", não pode haver um objeto (como o som é caracterizado) como um ser destacado do mundo. Tão pouco também há uma escuta independente do lugar de escuta, do mundo em que o ser é. Nesse sentido toda experiência de imagens perceptivas daquilo que se chama de som é uma experiência própria de determinados corpos que interagem em lugares específicos. Sem os corpos ou especificidades de tais lugares onde tais corpos vivem, a ideia de som se desliga de sua origem na escuta, se reifica e se fetichiza.

É próprio, e mesmo uma estratégia, do regime explicativo vigente por toda a Modernidade essa perspectiva de desprezar especificidades dos corpos e lugares que fazem a escuta. A construção da noção de som descorporificada e des-situada durante toda a Idade Moderna foi, e tem ainda sido, um recurso útil para a instituição e a manutenção de sistemas de dominação e exploração de povos colonizados pelos europeus desde o século XVI. O filósofo Enrique Dussel, entre tantos outros autores, apresenta uma importante pista para compreender e encaminhar os estudos sobre como estão montados determinados mecanismos de dominação cultural, 
econômica e política a partir de conceitos fundamentais baseados na tal inversão lógica, que coloca a representação no lugar da experiência, que coloca o som no lugar da escuta. Ao encaminhar sua crítica à R. Descartes e o dualismo mente/corpo, Dussel esclarece como as especificidades dos corpos saem de cena na explicação sobre o conhecimento sobre a percepção. Ele aponta para a noção cartesiana de corpo como máquina pura e o papel que essa noção tem na formação das concepções ocidentais do mundo e suas experiências possíveis.

Essa máquina pura não irá assinalar a sua cor de pele nem a sua raça (evidentemente, Descartes só pensa a partir da raça branca) nem obviamente o seu sexo (também só pensa a partir do sexo masculino), que são de um europeu (não descreve nem se refere a um corpo colonial, de um índio, de um escravo africano ou de um asiático). A indeterminação quantitativa de toda a qualidade também será o início de todas as abstrações ilusórias do 'ponto zero' da subjetividade filosófica moderna e da constituição do corpo como mercadoria quantificável com um preço (como acontece no sistema da escravidão ou no do salário no capitalismo). (DUSSEL, 2010. Locais do Kindle 5774-5779).

A mesma exclusão que ocorre com os corpos acontece com os lugares nos quais esses corpos se constituem e fazem em seu viver. E assim se concebe um mundo no qual as diferenças dos corpos e seus lugares de vida são apagadas em favor de entidades abstratas e universais. Nesse mundo existe o som sem a escuta, sem os corpos que escutam nos lugares específicos. Nessa descrição de mundo é que se planeja o som, se desenha o som, e não se leva em consideração os corpos específicos que escutam em seus lugares de vida.

\section{CONCLUSÃO}

A partir da discussão acima se nota a necessidade de compreender o planejamento do som como o planejamento de experiência de pessoas específicas em lugares específicos. Ao superar o paradigma moderno o design de som tem de ser design de escuta para corpos diversos que vivem e interagem em lugares também diversos. E não se trata de desenhar e oferecer experiências de segregação de pessoas e lugares, mas diametralmente o contrário. Trata-se de planejar as experiências levando em conta as especificidades dos corpos, suas emoções, características físicas e seus hábitos de vida em lugares, que também possuem características próprias enquanto construções sociais historicamente em constituição, locais próprios de partilhas materiais e emocionais.

Ao aproximar perspectivas ontológicas e epistemológicas da fenomenologia com os estudos políticos sobre decolonialidade entende-se que as abordagens do paradigma moderno, como a do som longe da escuta, são exemplos das estratégias para manutenção de um status-quo submetido a lógicas de dominação, exclusão e exploração. Ao mesmo tempo também se vislumbra a possibilidade de emancipação e libertação dessas condições por conta de novas oportunidades de ação, a partir de novas concepções, que dessa vez levam em conta as pessoas e seus lugares de escuta e vida.

\section{REFERÊNCIAS}

DUSSEL, E. Meditações Anticartesianas sobre a origem do antidiscurso filosófico da modernidade. In: SANTOS, B. S.; MENESES, M. P. Epistemologias do Sul. São Paulo: Cortez Editora, 2010. Edição do Kindle. (Locais do Kindle 5774-5779).

INGOLD, T. Estar Vivo: ensaios sobre movimento, conhecimento e descrição. Petrópolis: Vozes, 2015.

MERLEAU-PONTY, M. Fenomenologia da Percepção. São Paulo: Martins Fontes, 1996. 
SCHAFER, R. M. The Soundscape: our sonic environment and the tuning of the world. New York: Knopf, 1977. 